\title{
AVALIAÇÃO DA QUALIDADE DE DIFERENTES MARCAS COMERCIAIS DE MILHO-PIPOCA ${ }^{1}$
}

\author{
Reginaldo Gomes Nobre², João Liberalino Filho ${ }^{3}$, Everardo Ferreira Praça ${ }^{4}$, \\ Nildo da Silva Dias $^{2} \&$ Miguel Ferreira Neto ${ }^{2}$
}

\begin{abstract}
RESUMO
Com o objetivo de avaliar a qualidade de diferentes marcas comerciais de milho-pipoca, desenvolveu-se um trabalho durante o período de setembro a dezembro de 1998. O delineamento experimental foi o de blocos inteiramente casualizados, com dez tratamentos e três repetições, em que os tratamentos constaram das marcas do milho-pipoca: Yoki, Hikari, Sinhá, Maitá, Dona Clara, Zaeli, Super Grão, Poty, Kero-Kero 1 e Kero-Kero 2. As características avaliadas foram: índice de capacidade de expansão (ICE), peso de 100 grãos, teor de umidade (TU) e análise sensorial (AS). Os resultados mostram que as marcas Zaeli, Yoki, Maitá e Dona Clara apresentaram alto ICE e preferência na AS, enquanto a marca Kero-Kero 2 teve o maior percentual de umidade e, com relação ao peso de 100 grãos, as marcas Yoki e Dona Clara mostraram os maiores pesos médios, embora não diferindo estatisticamente das marcas Sinhá, Zaeli e Kero-Kero 2.
\end{abstract}

Palavras-chave: milho-pipoca, qualidade, marcas do milho-pipoca

\section{EVALUATION OF THE QUALITY OF DIFFERENT COMMERCIAL BRANDS OF POPCORN}

\begin{abstract}
To evaluate the quality of different brands of commercial popcorn, a study was conducted during the period of September to December, 1998. A completely randomized blocks design was adapted with ten treatments and three replications. The treatments consisted of different brands of the popcorn: Yoki, Hikari, Sinhá, Maitá, Dona Clara, Zaeli, Super Grão, Poty, Kero-Kero 1 and Kero-Kero 2. The characteristics appraised were: index of expansion capacity (ICE), 100 grains weight, water content (TU) and sensorial analysis (AS). The results show that the Zaeli, Yoki, Maitá and Dona Clara presented high ICE and preference in AS, where as the Kero-Kero 2 showed the hightest percentage of water content and weight of 100 grains. The brands Yoki and Dona Clara presented higher mean weight, although statistically not differing with respect to Sinhá, Zaeli and Kero-Kero 2.
\end{abstract}

Key words: popcorn, quality, brands of the popcorn

Recebido em 08/11/1999, Protocolo 125/99

${ }^{1}$ Parte da monografia de Graduação apresentada pelo primeiro autor à Escola Superior de Agricultura de Mossoró-ESAM, como requisito para obtenção do título de Engenheiro Agrônomo

${ }^{2}$ Estudante de Pós-graduação em Engenharia Agrícola, DEAg/UFPB, Av. Aprígio Veloso, 882, CEP 59109 - 970, Campina Grande, PB. Fone: (0xx83) 333 2470. E-mail: nildodias@ deag.ufpb.br

${ }^{3}$ Prof. Titular, Departamento de Fitotecnia da ESAM, CP 12, CEP 59625 - 000, Mossoró, RN. Fone: (0xx84) 3174685

${ }^{4}$ Prof. Titular, Departamento de Química e Tecnologia da ESAM, CP12, CEP 69625 - 000, Mossoró, RN. Fone: (0xx84) 3122100 


\section{INTRODUÇÃO}

O milho-pipoca pertence à espécie botânica Zea mays L., e apresenta sementes duras e pequenas nas quais, quando aquecidas a $170^{\circ} \mathrm{C}$ aproximadamente, o óleo e a umidade exercem pressão sobre o pericarpo, até que ele se rompa, formando a pipoca. O milho-pipoca varia quanto ao formato (redondo, chato, pontiagudo) e a coloração (rosa, creme, vermelha, roxa, preta, azul etc.), sendo as cores branca e amarela as mais comuns (Zinsly \& Machado, 1978).

A característica de pipoqueamento é que o torna diferente dos demais tipos de milho e esta diferença, por sua vez, lhe conferem maciez e sabor, bastante apreciáveis (Zinsly \& Machado, 1978). Os autores comentam que a avaliação da qualidade do milho-pipoca é feita através da análise do índice de capacidade de expansão e, quanto maior for esta propriedade, maior também será o valor comercial do produto, devido estar associado à maciez da pipoca. Para que este milho seja comercializado, deverá apresentar índice de capacidade de expansão acima de 15 , pois abaixo deste valor a pipoca apresenta-se muito rígida e com muitos grãos sem "estourar".

De acordo com Sawazaki (1995) o índice de capacidade de expansão é afetado por várias propriedades físicas dos grãos, entre as quais se destacam o teor de umidade, o peso dos grãos, as injúrias mecânicas e a secagem rápida dos grãos.

Teores de umidade situados entre 10,2 e 13,4\% são os mais adequados para obtenção do índice máximo de capacidade de expansão (Krug et al., 1996).

Zinsly \& Machado (1978) relatam que as sementes de milho-pipoca, assim como as de milho comum, perdem o poder de germinação depois de armazenadas por dois ou três anos, mesmo sob condições adequadas de armazenamento, mas não perdem a capacidade de expansão, pois esta característica não está associada ao poder germinativo das sementes as quais, quando bem armazenadas, conservam sua capacidade de expansão por um período de 15 a 20 anos.

Levando-se em consideração o "montante" comercializado de milho-pipoca objetivou-se, neste trabalho, avaliar a qualidade de diferentes marcas comerciais desse milho.

\section{MATERIAL E MÉTODOS}

Este trabalho foi desenvolvido na microrregião de Mossoró, $\mathrm{RN}$, que abrange os municípios de Mossoró, Areia Branca, Baraúna, Grossos e Serra do Mel, no período de 1 de setembro a 11 de dezembro de 1998.

A aquisição das marcas de milho-pipoca foi efetuada em 16 estabelecimentos da microrregião, totalizando dez marcas diferentes (Yoki, Hikari, Sinhá, Maitá, Dona Clara, Zaeli, Super Grão, Poty, Kero-Kero 1 e Kero-Kero 2); essas marcas, recentemente produzidas, eram embaladas em sacos plásticos de $500 \mathrm{~g}$ e apresentavam coloração amarela e forma pontiaguda. É importante ainda ressaltar que, embora a aquisição das marcas de milho-pipoca tenham sido na microrregião de Mossoró, as mesmas são comercializadas nacionalmente.

Com base na utilização de três amostras de cada material (marcas de milho-pipoca) avaliaram-se as seguintes características: peso de 100 grãos, pesados em balança analítica de precisão e os resultados expressos em grama; teor de umidade, determinado através do método gravimétrico padrão, usando-se estufa com circulação forçada de ar a $105^{\circ} \mathrm{C}$ durante $24 \mathrm{~h}$ (Brasil, 1992) e os resultados foram expressos em percentagem; índice de capacidade de expansão (ICE), obtido através da utilização de volume padrão de $35 \mathrm{~mL}$ de grãos medidos em proveta de 500 $\mathrm{mL}$; em seguida, este material foi colocado em uma "pipoqueira" de fabricação brasileira, juntamente com $12 \mathrm{~mL}$ de óleo de soja, tendo como fonte de calor um fogão doméstico (chama média) e, após o completo pipoqueamento, determinou-se o volume de pipoca usando-se um becker de $2000 \mathrm{~mL}$. O ICE foi determinado pela relação entre o volume final de pipoca e o volume inicial de grãos. Avaliou-se, também, a preferência, em níveis de qualidade da pipoca (análise sensorial) utilizando-se dez provadores não treinados e não fumantes que, com base nas características de textura, sabor, aparência e cor da pipoca, atribuíram notas numa escala hedônica (Chaves, 1980).

O delineamento experimental foi o de blocos casualizados, com dez tratamentos e três repetições, em que os tratamentos constaram das marcas do milho-pipoca: Yoki, Hikari, Sinhá, Maitá, Dona Clara, Zaeli, Super Grão, Poty, Kero-Kero 1 e Kero-Kero 2. Os dados obtidos referentes às análises físicas foram submetidos à análise de variância, comparando-se as médias pelo teste de Tukey, a nível de 1 e ou 5\% de probabilidade (Gomes, 1976). A análise de variância foi realizada utilizando-se o software ASSISTAT 6.1 (Silva, 1996).

\section{RESULTADOS E DISCUSSÃO}

A Tabela 1 apresenta os valores médios referentes ao peso de 100 grãos, teor de umidade dos grãos, índice de capacidade de expansão e análise sensorial para as dez marcas de milho-pipoca estudadas. As médias e os coeficientes de variação apresentados nesta tabela são provenientes de três determinações.

As marcas Yoki e Dona Clara apresentaram os maiores pesos de 100 grãos, embora não diferindo estatisticamente das marcas Sinhá, Zaeli, Kero-Kero 2 e Hikari.

Tabela 1. Valores médios* do peso de 100 grãos (PG), teor de umidade dos grãos (TU),índice de capacidade de expansão (ICE) e da análise sensorial (AS) de diferentes marcas comerciais de milho-pipoca

\begin{tabular}{lcccc}
\hline Marcas & $\begin{array}{c}\text { PG } \\
(\mathrm{g})\end{array}$ & $\begin{array}{c}\text { TU } \\
(\%)\end{array}$ & $\begin{array}{c}\text { ICE } \\
\left(\mathrm{mL} \mathrm{mL}^{-1}\right)\end{array}$ & AS \\
\hline Yoki & $15,39 \mathrm{a}$ & $11,61 \mathrm{~b}$ & $26,57 \mathrm{ab}$ & 7,3 \\
Dona Clara & $15,24 \mathrm{ab}$ & $10,76 \mathrm{~d}$ & $23,33 \mathrm{ab}$ & 6,8 \\
Sinhá & $14,73 \mathrm{abc}$ & $12,49 \mathrm{a}$ & $22,57 \mathrm{ab}$ & 6,2 \\
Zaeli & $14,57 \mathrm{abcd}$ & $11,06 \mathrm{~cd}$ & $27,62 \mathrm{a}$ & 7,2 \\
Kero-Kero 2 & $14,31 \mathrm{abcd}$ & $12,82 \mathrm{a}$ & $23,33 \mathrm{ab}$ & 6,5 \\
Hikari & $14,38 \mathrm{abcd}$ & $11,86 \mathrm{~b}$ & $22,28 \mathrm{ab}$ & 6,7 \\
Super Grão & $14,12 \mathrm{bcd}$ & $10,95 \mathrm{~cd}$ & $21,43 \mathrm{ab}$ & 6,5 \\
Kero-Kero 1 & $13,79 \mathrm{~cd}$ & $8,89 \mathrm{e}$ & $19,81 \mathrm{~b}$ & 6,8 \\
Poty & $13,63 \mathrm{~cd}$ & $11,72 \mathrm{~b}$ & $21,43 \mathrm{ab}$ & 5,8 \\
Maitá & $13,41 \mathrm{~d}$ & $11,11 \mathrm{c}$ & $25,72 \mathrm{ab}$ & 7,1 \\
\hline MÉDIA & 14,36 & 11,33 & 23,41 & 6,69 \\
TESTE F & Sig. $1 \%$ & Sig. $1 \%$ & Sig. 5\% & $\mathrm{ns}$ \\
DMS & 1,16 & 0,34 & 7,13 & 1,92 \\
CV (\%) & 2,76 & 1,04 & 10,41 & 19,68 \\
\hline As médias seguidas de mesma letra não diferem pelo teste de Tukey
\end{tabular}


As diferenças de valores entre as marcas em relação ao peso de 100 grãos são devidas, possivelmente, ao fato desta característica apresentar alta variabilidade (Sawazaki, 1995). $\mathrm{O}$ autor relata que esta característica apresenta correlação positiva com o tamanho da flor da pipoca e com o ICE.

Com relação aos valores médios do teor de umidade dos grãos, verifica-se que a marca Kero-Kero 2 e Sinhá apresentaram maior porcentagem de umidade. A porcentagem de umidade dos grãos é um dos principais fatores que afetam a capacidade de expansão, confirmando o trabalho de Nascimento \& Bouteux (1994) que, estudando a população de milho-pipoca CNPH 001 com grãos apresentando diferentes teores de umidade $(6,7 ; 8,6$; 10,$2 ; 13,9$ e $18,2 \%$ ) puderam comprovar que grãos com teor de umidade de 10,2\% apresentaram o mais elevado $\operatorname{ICE}(17,6)$.

Neste trabalho os teores de umidade que se encontram entre 10,76 e $12,82 \%$ apresentaram os melhores índices de capacidade de expansão.

Os resultados obtidos corroboram com os encontrados por Krug et al. (1996), Zinsly \& Machado (1978) e Sawazaki et al. (1986a) os quais demonstram que o teor de umidade deve estar situado entre 10,5 e 11,5\% para obtenção de máximo índice de capacidade de expansão.

Para a característica índice de capacidade de expansão, observou-se que a marca Zaeli apresentou o maior $\operatorname{ICE}(27,62)$ embora não tenha diferido estatisticamente das marcas Yoki, Maitá, Dona Clara, Kero-Kero2, Sinhá, Hikari, Super Grão e Poty. Este resultado ratificou o trabalho de Germani et al. (1996) que, trabalhando com 15 cultivares de milho pipoca, observaram os melhores ICE acima de 19. Apesar da marca Kero Kero 1 ter apresentado baixo teor de umidade de grãos, teve um ICE relativamente alto.

Zinsly \& Machado (1978) comentam que, para que o milho-pipoca seja comercializado, seu ICE deve estar acima de 15 , pois, abaixo deste índice, a pipoca se apresenta muito rígida e com muitos grãos sem estourar. Por outro lado, Santiago et al. (1996) encontraram os melhores ICE acima de 20 e teores de umidade entre 12 e 13,9\% quando trabalharam com três cultivares de milho-pipoca (MF-1001, Colorado e Pirapoca Amarela). Levando-se em consideração esses aspectos, verifica-se que todas as marcas de milho pipoca estudadas apresentaram ICE satisfatório, embora os teores de umidade encontrados estejam abaixo da faixa de variação indicada pela literatura para obtenção do máximo ICE.

As médias de todas as marcas referentes à análise sensorial estão apresentadas na Tabela 1, em que se observou que a maior média com relação a esta característica foi apresentada pela marca Yoki, embora não diferindo estatisticamente das demais. Baixos resultados na análise sensorial podem ser atribuídos à grande quantidade de restos florais aderidos aos grãos, ao tamanho da ponta do grão e ao baixo ICE, pois esta característica está relacionada à maciez da pipoca; então, quanto menor o ICE, pior a textura da pipoca.

O ICE está ligado diretamente com à maciez da pipoca e, quanto maior este índice, melhor a qualidade da pipoca (Zinsly \& Machado, 1978) e, tal afirmação também foi comprovada neste trabalho.

Segundo Sawazaki (1986b) o tamanho da ponta do grão e dos restos florais que ficam aderidos à pipoca, é variável entre os tipos de grão e pode depreciar a qualidade da pipoca.

Zinsly \& Machado (1978) comentam que a seleção do milho-pipoca de alto ICE deve ser dirigida para grãos de pericarpo grosso, pois esta propriedade tem influência no tamanho da flor e nos restos de fragmento que depreciam a qualidade da pipoca.
Os grãos de preferência do mercado são os amarelos, que possuem pericarpo incolor, endosperma amarelo a laranja e aleuroma incolor, amarelo ou marrom (Sawazaki, 1995). Neste trabalho, os provadores confirmaram tal preferência.

\section{CONCLUSÕES}

1. As marcas Zaeli, Yoki, Maitá e Dona Clara apresentaram alto índice de capacidade de expansão (ICE) e preferência na análise sensorial (AS).

2. As marcas Yoki e Dona Clara apontam os maiores pesos de 100 grãos, embora não diferindo estatisticamente das marcas Sinhá, Zaeli, Kero-Kero 2, Hikari.

3. A marca Kero-Kero 2 apresentou o maior percentual de umidade.

\section{REFERÊNCIAS BIBLIOGRÁFICAS}

BRASIL. Ministério da Agricultura e Reforma Agrária. Regras para análise de sementes. Brasília: SNDA/DNDV/CLAV, 1992. 365p.

CHAVES, J.B.P. Avaliação sensorial de alimentos. Viçosa, MG: UFV, 1980.69p.

GERMANI, R.; PACHECO, C. A. P.; CARVALHO, C. W. P. Características físicas e químicas das principais cultivares de milho pipoca plantados no Brasil. In: CONGRESSO NACIONAL DE MILHO E SORGO, 21, Londrina, PR, 1996. Anais... Londrina: EMBRAPA, 1996. p.344.

GOMES, F.P. Curso de estatística experimental. Piracicaba: ESALQ, 1976.430p.

KRUG, C.A.; CONAGIN, A.; JUNQUEIRA, A.A.B. Cultura e adubação do milho. São Paulo, SP: Ed. Instituto de Potassa. 1996. p. $96-8$.

NASCIMENTO, W.M.; BOUTEUX, L.S. Influência do grau de umidade do grão na capacidade de expansão do milho-pipoca. Horticultura Brasileira, Brasília, v.12, n.2, p. 179 - 180, 1994.

SANTIAGO, A. D.; MACHADO, J.R.; ROÇA, R.O. Sistema de secagem dos grãos e qualidade da pipoca de três cultivares de milho-pipoca. In: CONGRESSO NACIONAL DE MILHOE SORGO, 21, Londrina, PR, 1996. Anais... Londrina: EMBRAPA, 1996. p. 191.

SAWAZAKI, E. Melhoramento do milho-pipoca. Campinas, SP; Bragantia. 1995. 19p.

SAWAZAKI, E.; GALLO, P.B.; SORDI, G. de; LONGO, L.S. Estudo da capacidade de expansão em cruzamentos dialélicos entre variedades de milho-pipoca. In: CONGRESSO NACIONAL DE MILHO, 15 Maceió, 1984. Anais... Brasília: EMBRAPA - DDT, 1986a. p. 157-160.

SAWAZAKI, E.; MORAIS, J.F. de LAGO, A.A. Influência do tamanho e umidade do grão na expansão da pipoca South American Mushroom. Bragantia, Campinas, v.45, n.2, p.363 370, 1986b.

SILVA, F. de A. S. e. The ASSISTAT software: Statistical assistance. In: INTERNATIONAL CONFERENCE ON COMPUTER, 6, Cancun, 1. Anais... American Society of Agricultural Engineers, 1996, p.294-298.

ZINSLY, J.R.; MACHADO, J.A. Milho-pipoca. In: Melhoramento e produção de milho no Brasil. Piracicaba, ESALQ: Fundação Cargill. 1978. p. 339-348. 